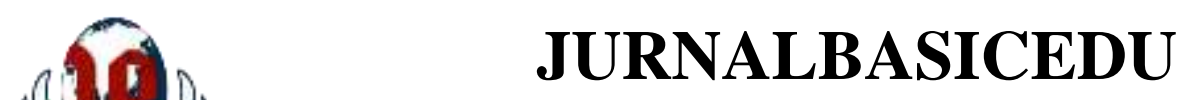

Volume 6 Nomor 1 Tahun 2022 Halaman 1324 - 1330

Research \& Learningin Elementary Education

https://jbasic.org/index.php/basicedu

\title{
Implementasi dan Manfaat Ice breaking untuk Meningkatkan Minat Belajar Siswa Sekolah Dasar
}

\author{
May Muna Harianja ${ }^{1 凶}$, Sapri $^{2}$ \\ Universitas Islam Negeri Sumatera Utara, Indonesia ${ }^{1,2}$ \\ E-mail: maymunaharianja99@gmail.com ${ }^{1}$, sapri@ uinsu.ac.id ${ }^{2}$
}

\begin{abstract}
Abstrak
Kejenuhan peserta didik adalah hal biasa dan kerap terjadi ketika proses belajar mengajar berlangsung. Hal ini sangat wajar karena peserta didik masih dalam usia bermain. Oleh sebab itu, guru harus mempelajari metode Ice breaking. Tujuan dilakukannya penelitian ini ialah untuk mengetahui implementasi dari penerapan Ice breaking, manfaat dari penerapan Ice breaking, serta hubungan antara penerapan Ice breaking dengan menarik minat peserta didik. Penelitian kualitatif merupakan model penelitian yang diterapkan dalam penelitian ini. Data dikumpulkan dengan teknik analisis melalui dokumentasi. Teknik analisis data yaitu analisis beberapa artikel jurnal atau karya tulis seseorang. Hasil penelitian menunjukkan bahwa (1) Ice breaking dapat diterapkan pada semua mata pelajaran, termasuk pendidikan nonformal. Ice breaking dapat disatukan atau dipadukan dengan model pembelajaran Realistik Setting Kooperatif (Resik) dan model pembelajaran lannya. (2) Dengan diterapkannya Ice breaking dapat menarik minat belajar siswa, motivasi belajar, daya serap, hasil belajar serta kemampuan komunikasi matematis. (3) manfaat yang didapat dari diterapkannya Ice breaking ini adalah untuk menghilangkan kejenuhan, kebosanan, serta rasa mengantuk dengan hal sederhana yang dapat dilakukan oleh setiap orang tanpa perlu keterampilan yang mumpuni.
\end{abstract}

Kata Kunci: Ice breaking, Implementasi, Minat belajar, Manfaat ice breaking

\begin{abstract}
Student saturation is common and often occurs when the teaching and learning process takes place. This is very reasonable because students are still at playing age. Therefore, teachers must learn the Ice breaking method. The purpose of this research is to find out the implementation of Ice breaking implementation, the benefits of Ice breaking implementation, and the relationship between Ice breaking implementation and attracting students' interest. Qualitative research is a research model that is applied in this study. Data were collected by analytical techniques through documentation. The data analysis technique is the analysis of several journal articles or someone's writings. The results showed that (1) Ice breaking can be applied to all subjects, including non-formal education. Ice breaking can be combined or combined with the Cooperative Setting Realistic learning model (Resik) and other learning models. (2) With the implementation of Ice breaking, it can attract students' interest in learning, learning motivation, absorption, learning outcomes and mathematical communication skills. (3) the benefits obtained from the implementation of Ice breaking are to eliminate boredom, boredom, and sleepiness with simple things that can be done by everyone without the need for qualified skills.
\end{abstract}

Keywords:Ice breaking, Implementation, Interest in learning, Benefits of ice breaking.

Copyright (c) 2022 May Muna Harianja, Sapri

$\triangle$ Corresponding author :

Email: maymunaharianja99@gmail.com

DOI : https://doi.org/10.31004/basicedu.v6i1.2298

ISSN 2580-3735 (Media Cetak)

ISSN 2580-1147 (Media Online)

Jurnal Basicedu Vol 6 No 1 Tahun 2022

p-ISSN 2580-3735 e-ISSN 2580-1147 
1325 Implementasi dan Manfaat Ice breaking untuk Meningkatkan Minat Belajar Siswa Sekolah Dasar May Muna Harianja, Sapri

DOI: https://doi.org/10.31004/basicedu.v6i1.2298

\section{PENDAHULUAN}

Model pembelajaran menjadi salah satu faktor pendukung dalam proses mentransfer ilmu dari guru terhadap peserta didik.Seorang guru juga harus memiliki strategi belajar mengajar yang tepat (Prihatini, 2017). Metode konvensional sudah tidak relevan untuk digunakan (Itqan, 2018). Oleh sebab itu, guru dituntut agar mengasah kemampuan dalam memilih dan dapat menerapkan model pembelajaran dengan benar. Agar penggunaan model pembelajaran yang tepat dapat mempengaruhi proses pembelajaran yang efektif dan efesien serta mampu mewujudkan tujuan dari pembelajaran.

Terdapat beberapa model pembelajaran yang biasa diterapkan guru dalam pembelajaran. Seperti examples non examples, jigsaw, numbered heads together, cooperative script, think pair and share, Role Playing, make a match, student facilitator and explaining, student teams achievement divisions (STAD), Mind Mapping, demonstration, debate, problem based introduction (PBI), snowball Throwing, talking stick, ice breaking, grup investigation, course review horay, dan masih banyak lagi model pembelajaran yang bisa diterapkan dan dipelajari agar proses pembelajaran lancar dan tiada hambatan.

Dalam pembelajaran minat belajar merupakan salah satu hal yang penting (Dasar, 2021). Karena ketika minat dari peserta didik telah muncul, maka proses pembelajaran akan lebih menyenangkan. Terkadang anak didik bisa kurang fokus ketika pembelajaran berlangsung, hal ini dapat disebabkan oleh kurang adanya minat yang terlihat ketika peserta didik mengikuti pembelajaran. Untuk memenculkan minat siswa, maka guru dapat menerapkan ice breaking baik diawal pembelajaran, di sela-sela, maupun di akhir proses pembelajaran supaya peserta didik kembali fokus dan mampu menerima pelajaran dengan baik.

Ice breaking ini sendiri adalah kegiatan yang diterapkan oleh setiap orang untuk menarik fokus perhatian serta mencairkan suasana di dalam ruangan menjadi keadaan yang semula yaitu keadaan yang bersemangat (kembali kondusif) (Satriani et al., 2018). Dan semangat inilah yang menjadi modal setiap individu untuk melakukan suatu aktivitas (Kurniasari \& Setiawan, 2021). Guru dapat menerapkan ice breaking diawal pembelajaran agar lebih optimal hasil yang didapatkan serta disela-sela proses pembelajaran agar dapat menghilangkan kebekuan atau kejenuhan siswa yang dapat menyebabkan rasa ngantuk pada siswa dalam proses pembelajaran. Ice breaking digunakan untuk menciptakan suasana belajar dari pasif menjadi aktif, dari kaku menjadi gerak, dan jenuh menjadi riang (Mi \& Baten, 2020). Ada beberapa jenis kegiatan ice breaking yang dapat diterapkan diantaranya, yel-yel, games, menyanyi, tepuk tangan, humor, serta gerak anggota badan. Dengan berbantuan Ice breaking pembelajaran menjadi menyenangkan dan dapat mendorong minat belajar dari peserta didik (Prasiscka \& Putra, 2021).

Minat adalah tendensi seseorang dalam menyukai sesuatu (Jalilah, 2021). Minat berasal dari diri seseorang yang berupa rasa suka atau ketertarikan terhadap sesuatu serta tidak dipengaruhi orang lain (Yunitasari \& Hanifah, 2020). Menumbuhkan sejak awal minat belajar siswa dengan menjelaskan manfaat mempelajari materi yang akan diajarkan (Nurmaulidina \& Bhakti, 2020). Pada dasarnya minat merupakan proses penerimaan hubungan antara diri kita terhadap sesuatu dari luar diri kita, semakin dirasakan kuatnya hubungan tersebut maka semakin kuat minat terhadapnya. Minat juga merupakan kecenderungan dan kegairahan yang tinggi atau keinginan yag besar terhadap sesuatu (Prestasi \& Fisika, 2019). Ekspresi minat sendiri dapat ditunjukkan dengan kesukaan seorang peserta didik terhadap sesuatu dibandingkan dengan yang lainnya.Minat itu tergantung pada bagaimana proses yang diberikan ketika belajar. Supaya bisa membangkitkan minat anak didik maka guru dapat mengaitkan pelajaran yang akan diajarkan guru dengan kebutuhan di dalam keseharian anak didik, agar anak didik merasa bahwa pelajaran itu perlu ia pelajari untuk kehidupannya. Minat memiliki pengaruh yag cukup besar terhadap proses da pencapaian hasil belajar peserta didik (Tambunan, 2018), karena ketika minat tidak sesuai dengan pelajaran, maka siswa tidak akan pernah belajar dengan baik (Belajar, 2020). 
1326 Implementasi dan Manfaat Ice breaking untuk Meningkatkan Minat Belajar Siswa Sekolah Dasar May Muna Harianja, Sapri

DOI: https://doi.org/10.31004/basicedu.v6i1.2298

Dalam penelitian sebelumnya (Marzatifa \& Agustina, 2021), beliau juga membahas hal yang sama yaitu implementasi dan manfaat dari ice breaking ini, perbedaannya hanya terhadap apa yang mempengaruhinya.

Dalam kajian lain juga dikatakan bahwa minat adalah keadaan ketika seseorang memiliki perhatian lebih terhadap sesuatu dengan rasa ingin mencari tahu serta mau untuk mempelajarinya lebih dalam (Nisa et al., 2015). Salah satu dari faktor yang dapat memepengaruhi usaha seseorang adalah minat.

\section{METODE PENELITIAN}

Peneliti melakukan penelitian ini dengan metode penelitian kualitatif. Teknik pengumpulan data dengan dokumentasi, dari beberapa jurnal yang telah diteliti terdahulu serta diuraikan secara sistematis serta terstruktur (Marzatifa \& Agustina, 2021). Penelitian ini dilakukan dengan merujuk pada beberapa jurnal yang tercantum pada tabel 1 berikut ini :

Tabel 1. Jurnal yang Diteliti

\begin{tabular}{|c|c|c|}
\hline No & Nama dan Tahun & Judul \\
\hline 1 & (Rosmalah, Hasdiana, dan Satriani, 2019) & $\begin{array}{l}\text { "Pengaruh Ice breaking Terhadap Minat Belajar } \\
\text { Siswa Kelas V SD Negeri } 10 \text { Manurunge } \\
\text { Kecamatan Tanete Riattang Kabupaten Bone" }\end{array}$ \\
\hline 2 & (Agus Mulyana, 2020) & $\begin{array}{l}\text { "Restorasi Fokus Belajar Siswa melalui Ice } \\
\text { breaking" }\end{array}$ \\
\hline 3 & (Tiyara \& Amirudin, 2020) & $\begin{array}{l}\text { "Pengaruh Ice breaking Terhadap Motivasi } \\
\text { Belajar Siswa Pada Mata Pelajaran IPA di Kelas } \\
\text { III Sekolah Dasar Islam Terpadu } \\
\text { Nuurusshiddiiq Kedawung Cirebon"(Journal \& } \\
\text { Khoerunisa, 2020) }\end{array}$ \\
\hline 4 & (Ahmad Irfan Al Faruqi, 2016) & $\begin{array}{l}\text { "Meningkatkan Daya Serap Siswa Pada } \\
\text { Pembelajaran Geometri Menggunakan } \\
\text { breaking"(Pendidikan et al., 2016) }\end{array}$ \\
\hline 5 & (Anif, Diah \& Ocvi, 2020) & $\begin{array}{l}\text { "Penerapan Metode Ice breaking Dalam Melatih } \\
\text { Minat Siswa Terhadap Pembelajaran Tematik } \\
\text { Kelas } 5 \text { SD Negeri } 1 \text { Hadiluwih" }\end{array}$ \\
\hline 6 & (Roviani et al., 2020) & $\begin{array}{l}\text { "Perbandingan Kemampuan Komunikasi } \\
\text { Matematis Menggunakan Strategi Question } \\
\text { Student Have Antara Siswa Yang Diberi Sisipan } \\
\text { Ice breaking Dengan Siswa Yang Diberi Sisipan } \\
\text { Reinforcement" }\end{array}$ \\
\hline 7 & (Adnan, Sahlini, M.Husin, dan Rizki, 2020) & $\begin{array}{l}\text { "Pengaruh Ice breaking Terhadap Hasil Belajar } \\
\text { pada Pembelajaran Tematik" }\end{array}$ \\
\hline 8 & (As'ari, Sarmidin, dan Helbi, 2019) & $\begin{array}{l}\text { "Pengaruh Pembelajaran Game Ice breaking } \\
\text { Terhadap Motivasi Belajar Siswa Kelas V Pada } \\
\text { Mata Pelajaran Pendidikan Agama Islam di SD } \\
\text { Negeri 001 Pangkalan Kecamatan Pucuk } \\
\text { Rantau" }\end{array}$ \\
\hline 9 & (Luh et al., 2017) & $\begin{array}{l}\text { "Pengaruh Model Pembelajaran } \\
\text { Setting Kooperatif (Resik) Dipadukan Dengan } \\
\text { Ice breaking Terhadap Hasil Belajar } \\
\text { Matematika" }\end{array}$ \\
\hline 10 & (Paradita, Rusyda, dan Fitri, 2021) & $\begin{array}{l}\text { "Pengaruh Teknik Ice breaking Terhadap Hasil } \\
\text { Belajar IPA Siswa Kelas IV SD 101/II Muara } \\
\text { Bungo Kabupaten Bungo" }\end{array}$ \\
\hline
\end{tabular}


1327 Implementasi dan Manfaat Ice breaking untuk Meningkatkan Minat Belajar Siswa Sekolah Dasar May Muna Harianja, Sapri

DOI: https://doi.org/10.31004/basicedu.v6i1.2298

\section{HASIL DAN PEMBAHASAN}

\section{a) Implementasi Ice breaking Dalam Pembelajaran}

Implementasi dari diterapkannya Ice breaking pada sepuluh jurnal diatas, maka didapatkan hasil penelitian bahwa menerapkan Ice breaking di dalam pembelajaran dapat menuai hasil yang sangat baik, dan diuraikan seperti dalam Tabel 2 berikut ini :

\section{Tabel 2. Hasil Analisis Jurnal}

Nama dan Tahun Hasil Penelitian

Peniliti menyimpulkan bahwa minat belajar siswa sesudah diterapkannya Ice breaking tergolong baik. Ditunjukkan dari antusias dan semangat peserta didik saat pembelajaran

(Rosmalah, Hasdiana, dan Satriani, 2019) menggunaan Ice breaking, yang dibuktikan melalui nilai rata-rata pre-test sebesar 47,35 sedangkan nilai rata-rata post-test sebesar 86,41 dari 31 peserta didik, dan memiliki pengaruh yang signifikan terhadap hasil belajar siswa.

Melakukan kegiatan Ice breaking dengan bervariasi dan ditujukan kepada sasaran yag tepatdapat membantu pengembalian (restorasi) konsentrasi belajar pada peserta

(Agus Mulyana, 2020) didik. Konsentrasi setiap peserta didik pasti berbeda-beda, oleh sebab itu guru harus memahami semua karakter dan keunikan siswanya agar dapat mengoptimalkan kegiatan pembelajaran.

Adanya efek atau pengaruh positif yang ditimbulkan oleh Ice breaking, dinyatakan dengan hasil penelitian di kelas III

(Tiyara \& Amirudin, 2020) SDIT Cirebon didapatkan dengan nilai persentase sebesar 90\% tergolong sangat baik dan artinya memiliki efek yang dapat membuat siswa termotivasi untuk mau belajar.(Journal \& Khoerunisa, 2020)

Melalui diterapkannya Ice breaking disela-sela belajar

(Ahmad Irfan Al Faruqi, 2016) siswa cukup mempunyai pengaruh terhadap daya serap siswa, dan setelah disisipkannya Ice breaking dapat mempengaruhi tingkat pemahaman siswa terhadap pembelajaran.

Melatih minat siswa SD terhadap pembelajaran dapat dilakukan dengan berbagai cara di dalam Ice breaking, seperti tepuk semangat, bernyanyi dll. Penelitian

(Anif, Diah \& Ocvi, 2020) menerapkan Ice breaking diawal, dipertengahan, dan juga diakhir pembelajaran agar memperoleh hasil yang maksimal. Ice breaking sangat berpengaruh pada siswa SD kelas V di Hadiluwih.

Penelitian ini menggunakan 2 kali eksperimen dengan sisipan bebeda. Eksperimen 1 disisipkan Ice breaking sedangkan eksperimen 2 disisipkan Reinforcement. Eksperimen 1 memperoleh hasil rerata sebesar 32 dari skor

(Reva, Sri, dan Wiwit, 2020) ideal 45, sedangkan eksperimen 2 memperoleh hasil ratarata sebesar 28 dari skor ideal 45. Maka dapat disimpulkan dengan disisipkannya Ice breaking dapat mempengaruhi kemampuan komunikasi matematis dengan menggunakan strategi Question Student Have disbanding dengan penyisipan Reinforcement.

Penelitian ini menggunakan tolak ukur hasil melalui

(Adnan, Sahlini, M.Husin, dan Rizki, 2020) kontrol dan eksperimen, dimana kelas experimen mendapatkan hasil nilai post-test sebesar 80,1 sedangkan 
1328 Implementasi dan Manfaat Ice breaking untuk Meningkatkan Minat Belajar Siswa Sekolah Dasar May Muna Harianja, Sapri

DOI: https://doi.org/10.31004/basicedu.v6i1.2298

\begin{tabular}{|c|c|}
\hline & $\begin{array}{l}\text { kelas control mendapatkan nila sebesar } 73,76 \text {. Artinya } \\
\text { adalah terdapat pengaruh yang baik ketika diterapkannya } \\
\text { Ice breaking, terlihat dari hasil kelas eksperimen tersebut. }\end{array}$ \\
\hline (As'ari, Sarmidin, dan Helbi, 2019) & $\begin{array}{l}\text { Diperoleh nilai rata-rata dari hasil data yang telah uji } \\
\text { sebesar 0,669\% yang sama dengan 6,69\%. Artinya } \\
\text { pembelajaran menggunakan jenis game dalam Ice breaking } \\
\text { dapat dapat member pengaruh terhadap motivasi belajar } \\
\text { siswa pada mata pelajaran Pendidikan Agama Islam sebesar } \\
6 \% \text { selebihnya dipengaruhi oleh variabel lain. }\end{array}$ \\
\hline $\begin{array}{l}\text { (Ni Luh Fitriani, I Wayan Wiarta, dan Ni } \\
\text { Wayan Suniasih, 2017) }\end{array}$ & $\begin{array}{l}\text { Dengan menggunakan model pembelajaran RESIK } \\
\text { (Realistik Setting Kooperatif) dipadukan dengan } \\
\text { menggunakan Ice breaking maka diperoleh hasil kelas } \\
\text { eksperimen sebesar } 83,30 \text { yang tergolong kategori B (baik) } \\
\text { dan kelas kontrol tanpa diberlakukan Ice breaking } \\
\text { memperoleh nilai sebesar } 72,30 \text { yang mana tergolong } \\
\text { dalam kategori C (cukup). Artinya bahwa ada efek yang } \\
\text { ditimbulkan secara spesifik ketika RESIK sebagai model } \\
\text { pembelajaran dipadukan dengan kegiatan Ice breaking. }\end{array}$ \\
\hline (Paradita, Rusyda, dan Fitri, 2021) & $\begin{array}{l}\text { Nilai pada kelas kontrol mendapat nilai rata-rata } 66,13 \text {, } \\
\text { sedangkan nilai pada kelas eksperimen mendapat rata-rata } \\
76,51 \text {. Artinya kegiatan Ice breaking dapat member } \\
\text { pengaruh hasil belajar siswa, bukti selanjutnya mengarah } \\
\text { kepada ketercapaian nilai KKM, setelah diterapkan Ice } \\
\text { breaking siswa mengalami peningkatan persentase } \\
\text { perolehan nilai KKM, yang awalnya siswa tidak mencapai } \\
\text { KKM sebayak 75\%, mengalami perubahan setelah } \\
\text { penerapan Ice breaking sebesar } 18 \% \text {. }\end{array}$ \\
\hline
\end{tabular}

Selain itu, Fransiska (2020) memberi saran untuk guru bahwa ketika mengawali pelajaran hendaknya menuntunpeserta didik bernyanyi, atau melakukan kegiatan Ice breaking lainnya, agar murid mau memperhatikan gurunya dalam menyampaikan pelajaran dan untuk menghindari siswa bermain-main saat pembelajaran. Pada saat siswa diajak untuk melakukan kegiatan Ice breaking, siswa nampak bersemangat melakukan kegiatan tersebut seperti yel-yel, bernyanyi serta tepuk-tepuk yang dapat mengubah suasana di dalam kelas menjadi suasana yang begitu ceria dan bersemangat yang pada akhirnya akan menumbuhkan minat belajar siswa untuk mau mengikuti pembelajaran.

\section{b) Manfaat Ice breaking Dalam Pembelajaran}

Ice breaking mempunyai beberapa manfaat sebagai berikut :

1. Kegiatan ini dapat dilakukan dan dipelajari oleh setiap orang tanpa harus memiliki keterampilan yang khusus.

2. Alat yang dapat member suasana kegembiraan dan keakraban serta perasaan bahagia antar peserta didik, maupun antara pendidik dan peserta didik.

3. Mampu menciptakan nuansa di dalam pendidikan, proses pembelajaran yang mempunyai makna serta menyenangkan(Arimbawa et al., 2017).

Penelitian yang sebelumnya sudah pernah dilakukan oleh (Marzatifa \& Agustina, 2021) yang memiliki pembahasan serupa dengan yang penulis teliti, beliau meneliti beberapa artikel jurnal yang di dalamnya mengandung unsur implementasi dan manfaat diterapkannya Ice breaking. Dalam penelitiannya beliau memperoleh hasil bahwa penerapan Ice breaking dapat mempengaruhi motivasi belajar siswa, daya serap siswa, minat belajar siswa, serta hasil belajar yang dapat menumbuhkan semangat belajar siswa. Hal ini berbanding lurus dengan hasil dari penelitian penulis, bahwa terdapat pengaruh yang dirasakan oleh setiap 
individu yang mendapat penggunaan Ice breaking pada proses belajarnya. Seperti berpengaruh pada minat belajar siswa, daya serap siswa, motivasi belajar siswa, model pembelajaran yang berbantuan kegiatan Ice breaking pun mendapat efek yang positif dalam menunjukkan hasil belajarnya. Maka dapat dikatakan bahwa Ice breaking memang mempunyai pengaruh yang baik dan signifikan terhadap proses pembelajaran. Khususnya yang masih menggunakan cara konvensional dalam mengajar harusnya dapat mengganti cara lama tersebut dengan menggunakan cara baru agar tujuan pembelajaran dapat dicapai.

Untuk proses pembelajaran kedepannya, hendaknya guru dapat mengubah cara mengajar yang monoton, agar siswa lebih bersemangat lagi untuk mau mengikuti pembelajaran didalam kelas. Dalam hal ini sebagian guru tidak mau repot menyelipkan Ice breaking di dalam proses pembelajaran, karena guru sudah nyaman dengan cara mengajar yang monoton yang identik dengan ceramah. Penelitian mengharapkan guru dapat merubah cara berpikirnya demi kemajuan pendidikan dan demi mencerdaskan anak bangsa.

Menurut pendapat saya, manfaat diterapkannya Ice breaking di dalam kelas ialah untuk memusnahkan kejenuhan, rasa bosan, serta rasa mengantuk dengan hal-hal sederhana ang dapat dilakukan oleh setiap orang tanpa perlu keterampilan yang mumpuni.

\section{KESIMPULAN}

Penggunaan Ice breaking dalam proses pembelajaran terlihat mudah, namun tidak semudah yang dibayangkan, masih membutuhkan keterampilan yang memadai, kreativitas yang dapat mendukung, serta pelatihan yang memadai agar tercapainya tujuan pembelajaran yag diinginkan. Sebaliknya, jika kegiatan Ice breaking dianggap mudah dan diterapkan dengan seadanya, maka tidak aka nada makna yang diperoleh. Manfaat Ice breaking sangat dirasakan oleh setiap individu yang menerapkannya, membuat susasana pembelajaran yang menyenangkan, kondusif, serta dapat membangkitkan minat dan motivasi peserta didik dalam proses pembelajaran.

\section{UCAPAN TERIMA KASIH}

Saya selaku peneliti ingin mengucapkan terimakasih kepada semua yang terlibat :

1. Allah SWT yang masih memberikan saya dengan izin-Nya kesempatan untuk hidup dan terus berjuang mengejar ridho orang tua dan ridho ilahi.

2. Ibu dan Ayah saya, yang telah susah payah sampai saat ini mensukseskan proses belajar saya sampai pada tingkat ini, serta sumber dana saya juga untuk masuk ke dunia pendidikan.

3. Dosen Pembimbing saya, yang telah mengajari saya hal-hal baru yang begitu berguna buat saya.

4. Teman, kerabat, sahabat, dan semua orang yang telah banyak member motivasi kepada saya agar saya mau dan berjuang sampai saat ini.

\section{DAFTAR PUSTAKA}

Arimbawa, I. K., Suarjana, I. M., \& Arini, N. W. (2017). Pengaruh Penggunaan Ice Breaker Terhadap Motivasi Belajar Siswa Sekolah Dasar Universitas Pendidikan Ganesha. 1, 1-8.

Belajar, M. (2020). Delta-Pi: Jurnal Matematika Dan Pendidikan Matematika Vol. 9 No. 2, 2020. 9(2), 120131.

Dasar, S. (2021). Jurnal Basicedu. 5(1), 88-101.

Itqan, M. S. (2018). Pendekatan Game Android Untuk Meningkatkan Minat Belajar Matematika Siswa Sekolah Dasar. 2(2), 161-170. 
1330 Implementasi dan Manfaat Ice breaking untuk Meningkatkan Minat Belajar Siswa Sekolah Dasar May Muna Harianja, Sapri

DOI: https://doi.org/10.31004/basicedu.v6i1.2298

Jalilah, S. R. (2021). Jurnal Basicedu. 5(6), 5946-5952.

Journal, E., \& Khoerunisa, T. (2020). Edubase: Journal Of Basic Education Pengaruh Ice breaking Terhadap Motivasi Belajar Siswa Pada Mata Pelajaran Ipa Di Kelas Iii Sekolah Dasar Islam Terpadu Nuurusshiddiiq Kedawung Cirebon. 1, 64-70.

Kurniasari, W., \& Setiawan, D. (2021). Meningkatkan Minat Belajar Siswa Menggunakan Model Blended Learning Berbasis Pada Google Classroom. 7(1), 141-148. Https://Doi.Org/10.31949/Educatio.V7i1.891

Luh, N., Dewi, F., Wiarta, I. W., \& Suniasih, N. W. (2017). Pengaruh Model Pembelajaran Realistik Setting Kooperatif ( Resik) Dipadukan Dengan Ice breaking Terhadap Hasil Belajar Matematika Jurusan Pendidikan Guru Sekolah Dasar, Fip Universitas Pendidikan Ganesha.

Marzatifa, L., \& Agustina, M. (2021). Ice breaking: Implementasi , Manfaat Dan Kendalanya Untuk Meningkatkan Konsentrasi Belajar Siswa. 6(2), 162-171. Https://Doi.Org/10.32505/AlAzkiya.V6i2.3309

Mi, D. I., \& Baten, A. S. (2020). Perbandingan Antara Metode Ice breaking Dengan Comparasi Terhadap Motivasi Belajar Siswa Kelas Iii Program Studi Pendidikan Guru Madrasah Ibtidaiyah ( Pgmi ) Sekolah Tinggi Ilmu Tarbiyah ( Stit ) Tahun Pelajaran 2019 / 2020 Perbandingan Antara Metode Ice breaking Dengan Comparasi Terhadap Motivasi Belajar Siswa Kelas Iii Di Mi Al-Khairiyah Sinar Baten Talangpadang. 1 .

Nisa, A., Studi, P., \& Konseling, B. (2015). Pengaruh Perhatian Orang Tua Dan Minat Belajar Siswa Terhadap Prestasi Belajar Ilmu Pengetahuan Sosial. Ii(1), 1-9.

Nurmaulidina, S., \& Bhakti, Y. B. (2020). Pengaruh Media Pembelajaran Online Dalam Pemahaman Dan. 6(November), 248-251.

Pendidikan, J. R., Irfan, A., \& Faruqi, A. (2016). Geometri Menggunakan Ice breaking. 2010, 53-60.

Prasiscka, A., \& Putra, F. G. (2021). Pengaruh Model Pembelajaran Arias Berbantuan Ice breaking Games Terhadap Kemampuan Penalaran Matematis Ditinjau Dari Gaya Belajar Peserta Didik. 8(1), 325-335.

Prestasi, T., \& Fisika, B. (2019). Hubungan Minat Belajar Terhadap Prestasi Belajar Fisika. 2.

Prihatini, E. (2017). Pengaruh Metode Pembelajaran Dan Minat. 7(2), 171-179.

Roviani, R., Hartini, S., \& Lestari, W. D. (2020). Perbandingan Kemampuan Komunikasi Matematis Menggunakan Strategi Question Student Have Antara Siswa Yang Diberi. 3, 47-53.

Satriani, N. P., Pudjawan, K., \& Suarjana, I. (2018). Pengaruh Model Pembelajaran Arias Dengan Selingan Ice Breaker Terhadap Hasil Belajar Ipa. 2(3), 312-320.

Tambunan, M. I. H. (2018). Pengaruh Minat Dan Kebiasaan Belajar Terhadap Hasil Belajar Biologi Siswa Sma Se-Kota Stabat. 2, 109-115.

Yunitasari, R., \& Hanifah, U. (2020). Edukatif: Jurnal Ilmu Pendidikan Pengaruh Pembelajaran Daring Terhadap Minat Belajar Siswa Pada Masa Covid-19. 2(3), 232-243. 